\title{
PERSPEKTIF KEBAHAGIAN MASYARAKAT YANG TINGGAL DEKAT TEMPAT PEMBUANGAN AKHIR SAMPAH DI SAMARINDA
}

\author{
HAPPINESS PERSPECTIVE TO SOCIETY LIVE NEAR LANDFILL GARBAGE \\ IN THE SAMARINDA
}

\author{
Oleh: \\ Hamka ${ }^{1}$ \\ Tri Astuti ${ }^{2}$
}

\begin{abstract}
ABSTRAK
Tempat pembuangan akhir selalu diidentifikasi dengan tempat kotor, bau dan jauh dari gaya hidup sehat, hal-hal seperti itu yang pada akhirnya tidak mendorong orang untuk tetap dekat dengan lokasi TPA (Tempat Pembuangan Akhir). Namun faktanya, ada banyak penduduk di dekat TPA. Meski jarak tinggal dekat dengan gunung-gunung sampah,masyarakat merasa hidup bahagia. Masyarakat yang tinggal dekat dengan timbunan sampah telah hidup selama lebih dari 10 tahun dan memilih untuk menetap di daerah tersebut. Oleh karena itu, kebahagiaan tidak harus berada di lingkungan yang indah dan bersih. Penelitian ini bertujuan untuk memperoleh informasi tentang dinamika kebahagiaan yang dirasakan oleh warga yang tinggal di tempat pembuangan akhir sampah yang digunakan dalam penelitian ini adalah metode kualitatif dengan pendekatan fenomenologi. Alat pengumpulan data yang digunakan adalah wawancara dan observasi. Adapun jumlah penelitian berjumlah empat keluarga yang memiliki rumah kira - kira 300 $\mathrm{m}$ dari tempat pembuangan akhir (TPA) sampah. Analisis penelitian digunakan dengan menggunakan pengkodean terbuka, pengkodean aksial dan pengkodean selektif. Berdasarkan hasil penelitian ditemukan bahwa orang yang tinggal di dekat TPA merasa bahagia karena orang di sana saling membantu meskipun keterbatasan baik tempat tinggal maupun makanan. Selain itu, masyarakat senang karena tempat kerja dekat dengan tempat tinggal dan tidak ada tekanan dalam bekerja.
\end{abstract}

Kata kunci: kebahagiaan; pembuangan akhir; Sampah Masyarakat

\section{ABSTRACT}

The final landfill is always identified with dirty, smelly and far from healthy lifestyles, things like that that ultimately do not encourage people to stay close to the landfill site. But in fact, there are many residents near the landfill. Although the distance living close to the mountains of waste, people feel happy life. People living close to the waste dump have lived for more than 10 years and have chosen to settle in the area. Therefore, happiness does not have to be in a beautiful and clean environment. This study aims to obtain information about the dynamics of happiness felt by residents living in landfills used in this study is a qualitative method with phenomenology approach. Data collection tools used are interviews and observation. The number of studies is four families that have houses about $300 \mathrm{~m}$ from landfill. The research analysis is used by using open encoding, axial

\footnotetext{
${ }^{1}$ Fakultas Psikologi, Universitas Muhammadiyah Kalimantan Timur, ham807@umkt.ac.id

${ }^{2}$ Fakultas Psikologi, Universitas Muhammadiyah Kalimantan Timur, tri497@umkt.ac.id 
coding and selective coding. Based on the results of the study it was found that people living near TPA feel happy because people there help each other despite the limitations of both housing and food. In addition, the public is happy because the workplace is close to where to live and there is no pressure in working.

\section{Keywords:Happiness, Final disposal, Trash, Community}

\section{PENDAHULUAN}

Kehidupan manusia yang tidak dapat terlepas dari sampah. Sampah didefinisikan sebagai suatu barang sisa yang sudah tidak dapat digunakan lagi. Seiring dengan perkembangan zaman dan kebutuhan manusia terdapat banyak sekali jenis sampah seperti sampah produksi, sampah rumah tangga dan sampah makanan. Jika sampah dibiarkan maka sampah akan menumpuk yang dapat menyebabkan bau dan tidak sehat terhadap lingkungan sekitarnya serta dapat menyebabkan penyakit pada warga sekitar. Sebilla (2014) berpendapat tempat sambah banyak terdapat nyamuk cikungunya yang menyebabkan beresiko penyakit demam cikungunya. Menurut Kementrian Negara Lingkungan Hidup (KNLH,2008) bahwa tempat sampah dampak lingkungan yang dikhawatirkan adalah menurunnya perilaku lingkungan, salah satu lingkungan yang dihasilkan adalah sampah yang harus mendapat penanganan dan pengelohan sehingga tidak menimbulkan dampak lanjutan yang berbahaya. Fathiras (2011) berpendapat volume sampah yang meningkat setiap tahun dipengaruhi oleh pertumbuhan penduduk, tingkat konsumsi masyarkaat dan sistem pengelolahan sampah. Hal ini menyebabkan sampah harus di buang dalam satu tempat yang disebut dengan tempat pembuangan akhir sampah. Selain itu, tempat pembuangan sampah juga harus jauh dari lingkungan tempat tinggal masyarakat. Di Indonesia, salah satunya kota Samarinda tempat pembungan sampah selalu berada di pinggiran kota yang jauh dari penduduk desa. Hanya saja tempat pembuangan akhir sampah di kota Samarinda dekat dengan tempat tinggal warga.

Pada dasarnya masyarakat yang tinggal dekat dengan tempat pembuangan akhir selalu dihubungkan dengan hal-hal yang bersifat negatif seperti bau dan lingkungan yang tidak sehat seperti penyakit yang mengintai mereka.Penelitianyang dilakukan oleh Thobing (2005) Secara umum orang beranggapan bahwa sampah adalah sesuatu barang atau benda yang sudah tidak berguna bagi dirinya. Sampah merupakan sesuatu yang kotor, bau, jelek; tidak berguna lagi sehingga secepatnya harus disingkirkan dan dibuangNamun pada kenyataannya masyarakat yang tinggal didekat tempat pembuangan sampah merasa bahagia.

Berdasarkandari hasilpreliminary researchwarga terlihat berkumpul di rumah salah satu warga sering bercanda dan tertawa dengan warga lain. Selain itu, masyarakat yang tinggal dekat dengan tempat pembuangan akhir (TPA) Samarinda justru merasa nyaman dan bahagia. Kebanyakan dari mereka justru membeli tanah di daerah tersebut dan ingin tinggal menetap disana. Data lain menunjukkan adalah penduduk ini merasa bahwa pekerjaan sebagai seorang pemulung justru dapat memenuhi kebutuhan mereka sehari - hari karena bisa 
dilakukan setiap hari dan tidak perlu merisaukan kontrak kerja jangka pendek terhadap pihak lain. $(\mathrm{O} 1, \mathrm{~W} 1, \mathrm{~S} 1)$.

Data-data diatas menunjukkan bahwa ada hal-hal positif dirasakan oleh masyarakat yang tinggal dekat dengan tempat pembuangan akhir di Samarinda. Kebahagiaan sendiri menurut Al-Farabi (dalam Zahidah \& Raihanah, 2011) kebahagiaan adalah kondisi hati yang dipenuhi dengan keyakinan dan berperilaku sesuai dengan keyakinan.

Konsep kebahagian dapat dilakukan dari berbagai perspektif. Masing-masing perspektif menjelaskan berbagai penjelasan yang berbeda - beda mengenai kebahagian itu sendiri. Dengan adanya penjelasan ini mendapatkan hasil yang berbeda - beda mengenai kebahagian yang dicapai. Para peneliti seringkali kesulitan merumuskan tentang konsep kebahagian. Kata kebahagiaan banyak memiliki makna yang beragam. Sering kali makna kebahagian (happiness) disamakan dengan baik (the good) atau hidup yang baik (the goodlife) (Eddington \& Shuman, 2005).

Kebahagiaan merupakan konsep yang luas, seperti emosi positif atau pengalaman yang menyenangkan, rendahnya mood yang negatif, dan memiliki kepuasan hidup yang tinggi (Diener, Lucas, Oishi, 2005). Seseorang dikatakan memiliki kebahagiaan yang tinggi jika mereka merasa puas dengan kondisi hidup mereka, sering merasakan emosi positif dan jarang merasakan emosi negatif.Selainitu kebahagiaan juga dapat timbul karena adanya keberhasilan individu dalam mencapai apa yang menjadidambaannya, dan dapat mengolah kekuatan dan keutamaan yang dimiliki dalam kehidupan sehari-hari, serta dapat merasakan sebuah keadaan yang menyenangkan (Diener, Lucas, Oishi, 2005).

Kebahagiaan memiliki empat komponen utama, seperti kepuasan dalam hidup secara umum, kepuasan terhadap ranah spesifik kehidupan, adanya afek yang positif, seperti mood dan emosi yang menyenangkan, dan ketiadaan afek negatif, seperti mood dan emosi yang tidak menyenangkan (Eddington \& Shuman, 2005). Keempat komponen utama ini, yaitu kepuasan hidup, kepuasan ranah kehidupan, afek positif, dan afek negatif, memiliki korelasi sedang satu sama lain, dan secara konseptual berkaitan satu sama lain. Namun, tiap-tiap komponen menyediakan informasi unik mengenai kualitas subyektif kehidupan seseorang (Diener, Scollon, \& Lucas, 2005). Afeksi positif dan afeksi negatif termasuk kedalam komponen afektif, sementara kepuasan hidup dan domain kepuasan termasuk kedalam komponen kognitif. Komponen-komponen utama kemudian dijelaskan kedalam beberapa elemen khusus. Afek positif meliputi kegembiraan, keriangaan hati, kesenangan, kebahagiaan hati, kebanggaan, dan afeksi. Sedangkan afek negatif meliputi munculnya perasaan bersalah,malu, kesedihan, kecemasan dan kekhawatiran, kemarahan, stress, depresi, dan rasa iri. Kepuasan ini pun dikategorikan melalui kepuasan hidup saat ini, kepuasan hidup pada masa lalu, dan kepuasan akan masa depan. Kepuasan ranah kehidupan muncul terhadap pekerjaan, keluarga, waktu, kesehatan, keuangan, dirinya sendiri, dan kelompoknya (Eddington \& Shuman, 2005). 
Seligman (2005) dalam bukunya berjudul Authentic Happiness: menciptakan kebahagian dengan psikologi positif, di terjemahkan dari Autenthic Happiness: using the newpositive to realize your potentioal for lasting fulfillment" menyatakan bahwa kebahagianjangkan panjang (K) merupakan hasil kontribusi dari rentang kebahagian (R), Lingkungan dan faktor - faktor yang berada di bawah pengendalian sadar seseorang $(\mathrm{P})$. Kebahagian yang di maksud Seligman (2005) merupakan jangka pangjang dan merupakan tingkat kebahagian secara umum yang dirasakan seseorang. Hal - hal yang bernilai negatif cenderung menghalangi peningkatan kebahagian seseorang. Rentang kebahagian menurut Seligman (2005) bersifat menentap dan terbeti pada tiap individu dalam tingkat yang berbeda - beda.

Terdapat banyak faktor yang mempengaruhi kebahagiaan salah satunya menurut Carr (2004), faktor-faktor yang mempengaruhi kebahagiaan yaitu kepribadian, budaya, pernikahan, dukungan sosial, persahabatan, kesehatan, agama dan kerjasama. Oleh sebab itu dalam penelitian ini untuk mengetahui perpektif kebahagian pada masyarakat yang tinggal di dekat tempat pembuangan akhir (sampah) di Samarinda.

\section{METODE PENELITIAN}

Metode yangdigunakan pada penelitian ini yaitu metode kualitatif dengan pendekatan fenomenologi. Pendekatan ini akan mampu mendapatkan hasil yang ingin diperoleh peneliti. Moloeng (2004) sendiri mendefinisikan penelitian kualitatif sebagai penelitian yang bermaksud untuk memahami fenomena tentang apa yang dialami oleh subjek penelitian.

\section{Informan Penelitian}

Pemilihan informan pada penelitian ini menggunakan theoritical sampling. Creswell (2007) menjelaskan bahwa metode ini merupakan metode yang sengaja digunakan untuk mendapatkan informan dengan data terbaik. Strauss dan Corbin (1990) menjelaskan bahwa theoretical sampling adalah sebuah proses dalam pengumpulan data, dimana penelitimengumpulkan, mengodekan, dan menganalisis, serta menentukan data apa yang perlu untuk dikumpulkan selanjutnya dan dimana data tersebut bisa didapatkan, untuk mengembangkan teori yang perlahan-lahan mulai Nampak.

Penentuan informan dalam penelitian ini didasarkan pada kriteria yaitu masyarakat yang tinggal di dekat tempat pembuangan akhir (TPA) sampah minimal 1 tahun dan informan tidak mengemas informasi, tetapi relatif memberikan informasi yang sebenarnya. Adapun jumlah partisipan dalam penelitiah ini berjumlan 4 orang. Karakteristik partisipan adalah jarak rumah dengan tempat pembuangan Akhir (TPA) kurang lebih sekitar $300 \mathrm{~m}$. Hal ini karena bau sampah sangat kuat dan kondisi lingkungan yang kurang bersih. Selain itu, rumah ini sering dilewati oleh mobil yang membawa sampah sehingga sering tercium bau sampah. 


\section{Metode Pengumpulan Data}

Pengumpulan data dalam penelitian ini menggunakan Wawancara dan Observasi. Wawancara pada penelitian ini menggunakan wawancara semi terstruktur dengan menggunakan interview guide dan akan dikembangkan pertanyaan lainnya jika diperlukan untuk mendapatkan data yang lebih dalam. Seangkan observasi yang dilakukan adalah peneliti yaitu observasi non partisipan, dimana peneliti menjadi bagian dari kelompok yang diamati hanya sebagai pengamat.

\section{Metode Analisis Data}

Menurut Goulding (2002) setelah tahap pengumpulan data selesai, selanjutnya adalah proses analisis data dengan teknik coding. Analisis data dilakukan dengan mengolah sumberdata tersebut dengan melakukan analisis data, mendalami pemahaman terhadap data, menyajikan data, dan kemudian melakukan interpretasi makna yang luas terhadap data temuan tersebut (Creswell, 2014). Coding data dirinci,dikonseptualisasikan dan diletakkan kembali bersamasama dalam cara baru open coding, axial coding dan selective coding (Goulding, 2002).

Open Coding adalah merinci, menguji, membandingkan, konseptualisasi, danmelakukan kategorisasi data yang dianalisis. Axial Coding: adalah suatu perangkat prosedur dimana data dikumpulkan kembalibersama dengan cara baru setelah open coding, dengan membuat kaitan antara kategori-kategori. Ini dilakukan dengan memanfaatkan landasan berpikir (paradigma) coding yang meliputi kondisi-kondisi, konteks-konteks, aksi strategi-strategi interaksi dan konsekuensi- konsekuensi. Selective Coding: adalah proses seleksi kategori inti, menghubungkan secarasistematis ke kategori-kategori lain, melakukan validasi hubungan-hubungan tersebut, dan dimasukkan ke dalam kategori-kategori yang diperlukan lebih lanjut untuk perbaikan dan pengembangan.

\section{PEMBAHASAN}

Pada dasarnya, masyarakat yang tinggal dekat pembuangan sampah merasa kurang nyaman dengan keadaan yang ada. Hal ini dikarenakan masyarakat sering membakar sampah di tumpukan sampah yang menyebabkan sesak nafas. Selain itu, faktor lain yang membuat tidak membuat nyaman tinggal di dekat sampah adalah belum masuknya saluran PDAM sehingga di masyarakat yang tinggal di dekat tempat pembuangan akhir (TPA) kekurangan air bersih. Hal ini masyarakat harus menampung air hujan untuk memenuhi kebutuhan sehari - hari. Kadang - kadang masyarakat membeli air bersih. Masyarakat juga sering mengalami penyakit gatal - gatal dan tercium bau sampah di sekitar rumah. Padahal Menurut Wibowo (2009) Kebersihan Lingkungan adalah salah satu tolak ukur kualitas hidup masyarakat.

Kebahagian dapat di artikan sebagai keadaan seseorang merasa tenang dan damai dalam kehidupan dan manfaat spiritual untuk ketenangan mental dan jiwa (Kwang, 2014). Perasaan tenang dan damai ini dapat memfokuskan individu 
untuk melakukan sesuatu dengan baik sehingga terbentuklah kedamaian dan kepuasan pada diri individu. Kedamaian inilah yang merupakan kebahagian. Kebahagian juga dapat diartikan sebagai kemampuan untuk menerima segala kenyataan yang ada walaupun tidak sesuai dengan harapan. Ketika seseorang menerima segala sesuatu yang tidak diharapkan, maka saat itu juga ia membebaskan dirinya dari segala perasaan negatif yang dapat merusak kebahagiaan itu sendiri.

Pada masyarakat yang tinggal didekat tempat pembuangan akhir (TPA) sampah kebahagian dapat dimaknai dengan rasa bersyukur atas segala yang ada. Sebagian besar masyarakat yang tinggal di dekat tempat merupakan pendidikan rendah. Namun, masyarakat tetap bahagia tinggal di dekat tempat pembuangan sampah karena dekat dengan pekerjaan. Hal ini dikarenakan, sebagian masyarakat yang tinggal di dekat tempat pembuangna akhir (TPA) sampah merupakan pendatang. Ada juga masyarakat yang tinggal di dekat tempat sampah sudah lama karena ikut orang tua. Pada dasarnya, masyarakat yang tinggal didekat tempat pembuangan sampah ingin lebih maju dan hidup menjadi lebih baik dari sekarang. Senada dengan pendapat Holland (1985) menyatakan Individu dengan minat Realistic menyukai aktivitas-aktivitas kerja yang bersifat praktis, cepat manangkap masalah dan mencar solusinya. Mereka enikmati kerja dengan tanaman, hewan, danmaterial-material lain yang terlihat, seperti kayu, mesin, alat, dll.Mereka juga menyukai kegiatan luar ruang. Seringkali individudengan minat realistic tidak menyukai perkerjaan yang terutamamelibatkan paper-work atau pekerjaan yang banyak berhubungan dengan orang lain.

\section{a. Faktor - faktor yang mempengaruhi kebahagian}

\section{Dekat dengan tempat kerja}

Masfufah (2012) mengatakan individu harus bekerja sesuai dengan minatnya dan lokasi yang diinginkan oleh individu dalam bekerja. Masyarakat yang tinggal di dekat tempat pembuangan akhir sampah merasa bahwa hidup di lingkungan yang penuh dengan sampah merupakan sebuah kebahagian karena dari tempat sampah masyarakat dapat memenuhi kebutuhan sehari - hari. Di lingkungan sampah, masyarakat dapat bekerja sebagai pemulung. Selain itu, anak - anak mereka juga dapat bekerja untuk membantu orangtuanya.

\section{Tidak ada tekanan dalam bekerja}

Masyakarat bekerja sebagai pemulung bebas untuk mengerjakan pekerjaannya tanpa adanya tekanan yang membuat masyarakat stress dalam bekerja. Menurut David dan Newstrom (2004) mendefinisikan stres kerja sebagai suatu kondisi yang mempengaruhi emosi, proses pikiran, dan kondisi fisik seseorangMasyakarat bebas untuk memilih waktu untuk bekerja di atas tumpukan sampah tanpa harus terikat oleh waktu. Selain itu, tidak ada yang memaksa masyarakat untuk bekerja di tumpukan sampah. Jika hari hujan atau jalan tergenang air maka masyarakat tidak akan bekerja. Hasil yang didapatkan 
dari pekerjaan akan dikumpulkan terlebih dahulu sebelum dijual ke pengumpul barang bekas.

\section{Saling Membantu}

Masyarakat dapat berinteraksi dengan tetangga yang berprofesi sebagai pemulung. Tetangga berusaha untuk saling membantu dengan masyarakat lain baik dalam pekerjaan sosial atau pekerjaan lain. Masyarakat yang tinggal di dekat tempat pembuangan akhir (TPA) Sampah juga mengerjakan bersama sama ketika pekerjaan bermanfaat untuk lingkungan sekitar. Selain itu, masyarakat yang tidak mampu untuk dikerjakan sendiri. Hal ini membuat hubungan antar masyarakat yang tinggal di dekat tempat pembuangan akhir (TPA ) Sampah menjadi lebih akrab. Seseorang yang meiliki empati dapat merasakan dan memahami apa yang dirasakan oleh oranglain. Empati terdiri dari respon afektif dan respon kognitif terhadap emosional yang sedang diraskaanoelh orang lain dan berkaitan dengan simpati, sebuat keinginan untuk memecahkan masalah orang lain dan memahami (prespective taking) orang lain (Baron \& Byrne, 2006)

\section{b. Dinamika psikologis kebahagian Masyarakat yang tinggal di tempat sampah}

1. Faktor Internal

a) Tidak ada tekanan dalam bekerja

Masyarakat bebas memilih waktu dalam bekerja karena tidak terikat dengan aturan yang berlaku. Selain itu, ketika hujan atau jalan becek masyarakat tidak turun untuk bekerja. Masyarakat juga tidak ada yang menekan dalam bekerja. Masyarakat beranggapan bahwa jika masyarakat yang tinggal dekat pembuangan sampah tidak bekerja maka mereka tidak mampu untuk mencukupi kebutuhan sehari - hari. Tekanan kerja sebagai kondisi yang dinamis di mana seseorang dikonfrontasikan dengan kesempatan, hambatan, atau tuntutan yang berhubungan dengan apa yang diinginkannya dan untuk itu keberhasilannya ternyata tidak pasti (Robbinsn, 2007)

b) Merasa damai dan tentram

Masyarakat yang tinggal di dekat tempat pembuangan akhir (TPA) sampah merasa damai dan tenang. Bagi masyarakat tinggal di dekat tempat pembuangan sampah adalah sebuah solusi karena dekat dengan tempat kerja. Hal ini, dikarenakan sebagian masyarakat yang tinggal dekat tempat pembuangan akhir (TPA) sampah adalah pendatang. Kebahagian dan kesengsaraan tentunya merupakan masalah kemanusiaan yang paling hakiki karena tujuan hidup manusia tiada lain adalah memperoleh kebahagian dan menghindari kesengsaraan (Majdid, 1995)

2. Faktor eksternal

a) Saling membantu

Masyarakat yang tinggal di dekat tempat pembuangan akhir (TPA) sampah selalu saling membantu jika ada masyarakat yang 
mendapat kesulitan. Selain itu, masyarakat juga sering berkunjung dari rumah satu ke rumah lain. masyarakat yang tinggal di dekat tempat pembuangan sampah juga selalu bercerita dengan tetangga yang lain. masyarakat biasa bercerita tentang permasalahan yang mereka hadapi. Hal ini senada dengan pendapat baron \& Byrne (2006) bahwa komponen afektif dari empati juga melibatkan simpati yaitu tidak hanya merasakan penderitaan orang lain tapi juga perhatian dan melakukan sesuait untuk mengurangi penderitaan tersebut.

b) Harapan

Masyarakat yang tinggal di dekat tempat pembuangan akhir (TPA) sampah, juga berharap dengan bekerja di tempat sampah dapat menjadikan hidup lebih baik. Hasil dari kerja di tempat sampah akan di belikan ke tanah dan akan dibangunkan rumah. Hal ini dikemukakan oleh Vroom (1965) yang menyatakan bahwa kekuatan yang memotivasi seseorang untuk bekerja giat dalam mengerjakan pekerjaannya tergantung dari hubungan timbal balik antara apa yang diinginkan dan dibutuhkan dari hasil pekerjaan itu. Teori harapan ini didasarkan atas : 1. Harapan (Expectancy), adalah suatu kesempatan yang diberikan akan terjadi karena perilaku. 2. Nilai (Valence) adalah akibat dari perilaku tertentu mempunyai nilai / martabat tertentu (daya/nilai motivasi) bagi setiap individu yang bersangkutan. 3 . Pertautan (Instrumentality) adalah persepsi dari individu bahwa hasil tingkat pertama Ekspektansi merupakan sesuatu yang ada dalam diri individu yang terjadi karena adanya keinginan untuk mencapai hasil sesuai dengan tujuan.

\section{KESIMPULAN}

Berdasarkan penelitian diatas, maka dapat disimpulkan bahwa pada dasarnya masyarkat yang tinggal didekat tempat pembuangan akhir (TPA) sampah merasa kurang nyaman karena adanya bau sampah, orang yang membakar sampah sehingga asapnya untuk mengganggu masyarakat dan adanya penyakit gatal - gatal pada kulit. Namun masyarakat yang tinggal di dekat tempat pembuangan sampah tetap merasa bahagia karena dekat dengan pekerjaan. Masyarakat yang tinggal di dekat tempat pembuangan akhir juga merasa bahagia karena masyarakat yang bekerja tidak terikat waktu tidak mengalami tekanan. Selain itu, masyarakat juga merasa bahagia karena masyarakat yang tinggal di dekat tempat pembuangan akhir (TPA) sampah saling membantu walaupun dengan keterbatasan ekonomi.

Saran bagi Masyarakat yang tinggal didekat tempat pembuangan akhir (TPA) sampah sebaiknya membuat tinggal sedikit lebih jauh dari tempat pembuangna akhir (TPA) sampah. Hal ini dikarenakan agar terhindar dari bau sampah dan menghindari orang yang membakar sampah agar tidak terganggu dengan orang yang membakar sampah. Selain itu, masyarakat yang tinggal di tempat sampah melakukan kerja sama untuk membuat penampungan air bersih agar bisa di manfaatkan bersama. 


\section{DAFTAR PUSTAKA}

Ariana, P.I.M. (2011). Respons Masyarakat Setempat Terhadap Keberadaan Tempat Pembuangan Akhir Di Desa Temesi Kabupaten Gianyar. Tesis. Program Studi Kajian Budaya Universitas Udayana Denpasar.

Azhari, K.S. (2009). Sketsa Masyarakat Pemulung Kota Bandung. Jurnal Sosioteknologi, 8(17), 696-701.

Baron, R.A \& Byrne, D.(2006). Psikologi sosial. (Edisi 11).Jakarta :Erlangga

Carr, A. (2004). Positive Psychology, The Science of Happiness and Human Strength. New York: Brunner Routledge.

Creswell, J. W. (2007). Qualitative Inquiry \& Research Design, Choosing Among FiveApproaches, (2nd Edition). Unites States of America: Sage Publications, Inc.

Creswell, J.W. (2012).Educational Research: planning, conducting, and evaluating quantitative and qualitative research. Nebraska: Pearson.

Davis, K.D.N. (2004), Perilaku dalam organisasi, (Edisi 7), Bahasa Indonesia, Jakarta, Erlangga.

Diener, E., Lucas, R. E., \& Oishi, S. (2005). Subjective well-being: The science of happinessand life satisfaction. In C. R. Snyder \& S. J. Lopez (Eds.), Handbook of positive psychology (2nd ed.), (pp. 63-73). New York: Oxford University Press.

Eddington,N \& Shuman, R. (2005). Subjective Well Being (Happiness). Continuing Psychology Education: 6 Continuing Education Hours. November 28, 2017 dari http://www.texcpe.com/cpe/PDF/cahappiness.pdf

Fhatiras, N. (2011). Analisis Pengelolaan sampah di tempat pembuangan akhir pasir sembung kabupaten cianjur ((Aplikasi Model IPAT), skripsi, Departemen Ekonomi Sumberdaya dan Lingkungan, Fakultas Ekonomi dan Manajemen, IPB Bogor.

Goulding, C. (2002). A Practical Guide for Management, Business and Market Research. London : Sage Publications.

Holland, J. (1985), Making a vacation Choices A theory of vocational Personalitis and work Environment, Englewood Cliff: Prentice Hall

Hurlock, E. B. (2000). Psikologi Perkembangan. Jakarta: Erlangga. 
Kementrian Negara Lingkungan Hidup (2008). Status lingkungan hidup,Jakarta: $\mathrm{KNLH}$

Kwang Ng, Y. (2014), Happiness, Life Satisfaction, or Subjective Well-being? A Measurement and Moral Philosophical Perspective, Winsemius Professor, Division of Economics, Nanyang Technological University. Singapore:

Majdid, N. (1995), Konsep - Konsep kebahagian dan kesengsaraan, Yayasan Paramadina, Jakarta:Yayasan Paramadina

Masfufah, R. (2012) Bimbingan Dan Konseling Islam Dengan Rational Emotive Behavior Therapy Dalam Menumbuhkan Minat Kerja Pada Remaja: Studi Kasus Seorang Remaja Lulusan Pondok Pesantren Yang Belum Bekerja Di Desa Sekaran skripsi - UIN Sunan Ampel Surabaya.

Moleong, L. J. (2004). Metodologi Penelitian Kualitatif. Bandung: PT. Remaja Rosdakarya.

Nurdin, M., (2004),Kiat Menjadi Guru Profesional, Jogyakarta:Prismasophie

Robbins, S. (2007). Organizational behavior.US:Printicle Hall.

Sabella, S. (2014), Risiko Gangguan Kesehatan Pada Masyarakat Di Sekitar Tempat Pembuangan Akhir (Tpa) Sampah Tanjungrejo Kabupaten Kudus, Skripsi, Jurusan Ilmu Kesehatan Masyarakat Fakultas Ilmu Keolahragaan, Universitas Negeri Semarang.

Seligman, M. E. P. (2005) Authentic Happiness; Menciptakan Kebahagiaan dengan Psikologi Positif. Terjemahan. Bandung: PT Mizan Pustaka

Strauss, A., \& Corbin, J. (1990). Basis of Qualitative Research: Grounded Theory Procedure and Techniques. London: Sage Publications

Soemirat, J. (2011). Kesehatan Lingkungan. Yogyakarta: Gadjah Mada Universitas Press.

Thobing \& Imran SL (2005, Juni). Dampak Sampah Terhadap Kesehatan Lingkungan Dan Manusia, Makalah pada Lokakarya "Aspek Lingkungan dan Legalitas Pembuangan Sampah serta Sosialisasi Pemanfaatan Sampah Organik sebagai Bahan Baku Pembuatan Kompos" Kerjasama Universitas Nasional dan Dikmenti DKI, Jakarta.

Vroom., Victor H, (1964), Work and motivation, New york : John Willey and Sons.

Wibowo, I. 2009. Pola Perilaku Kebersihan: Studi Psikologi Lingkungan Tentang Penanggulangan Sampah Perkotaan. Jurnal Makara, 13(1), 37-47. 
Hamka \&Tri Astuti,Perspektif Kebahagiaan Masyarakat Yang Tinggal Dekat TPA Sampah Di Samarinda

Zahidah \& Raihanah. (2011). The Model of Wellbeing in Family Life from Islami Perspective. Jurnal Fiqh, 8, 25-44. 